\title{
The Kitchen is a Laboratory: Experimental Science Activities Based on Food and Cooking
}

Paulina Mata

REQUIMTE/CQFB, Departamento de Química, Faculdade de Ciências e Tecnologia, Universidade Nova de Lisboa, Caparica, Portugal •mpm@fct.unl.pt

\begin{abstract}
Since 2001, a group of Portuguese scientists has been using experiments with food and cooking to attract the interest of the public, and particularly young people, in science and scientific activities. These science dissemination activities, entitled A Cozinha é um Laboratório (The Kitchen is a Laboratory) have been received with great interest and very positive feedback by the general public, as well as by schools in all levels of education. Subsequently, this approach was also used by the Portuguese team of the Pollen: Seed Cities for Science project to promote inquiry-based science education in primary schools and engage families and the community in this process. This paper presents the activities conducted as part of these initiatives, which have already resulted in two books.
\end{abstract}

\section{Introduction}

In early 2006, the project Pollen: Seed Cities for Science (Pollen, n.d.) was launched. It focused on creating 12 Seed Cities - educational territories that support science education through the commitment of the whole community - throughout the European Union. The primary objective of this project was to promote inquiry-based science education (IBSE) (Harlen, 2004) inside and outside classrooms, using formal and informal learning opportunities, while simultaneously engaging families and communities.

The Portuguese Seed City was Sacavém, a small town on the outskirts of Lisbon with a large Luso-African community. Family comes first when one wants to involve the community in science education, and the role of the Portuguese team was to work specifically on creating an environment for learning at home, in which families might get involved in the process of promoting scientific culture. Because the children participating in the project came from low-income families not used to collaborating in school activities, a key initial aim was to change attitudes to, and perceptions of, science. Furthermore, most of the primary school teachers involved in the project had very limited training in science and did not feel confident in their skills in this area, and thus an additional aim was to build capacity and confidence among teachers as well.

The approach to follow should motivate teachers and families to get involved in the project and to work on experimental science with satisfaction and pleasure. It should also be directly related to the daily life of families in order to make scientific concepts more accessible and meaningful. Considering that within this community even primary school science was a foreign culture (Aikenhead \& Jegede, 1999), it was important to reduce the feeling of foreignness and to make the process a two-way exchange based on mutual respect. 
In light of all these constraints, it was decided to focus on IBSE activities that mainly had food and cooking as a starting point. This decision was guided by the fact that some elements of the Pollen team had been previously involved in projects of introduction of experimental science education in pre-school, junior and middle level schools (Mata, Bettencourt, Lino \& Sousa-Paiva, 2004), and also in the project The Kitchen is a Laboratory, which involved using the same kind of approach for science dissemination activities (Ciência Viva, n.d.-a; Mata, Noronha, Gomes da Costa, Guerreiro \& Loureiro-Dias, 2007).

\section{The project The Kitchen is a Laboratory and its outcomes}

In 2001, on the basis of the assumption that science communication should be a component of the work done by those involved in the development of science, Ciência Viva, an agency for the promotion of scientific and technological culture among the Portuguese population (Ciência Viva, n.d.-b), invited Portuguese scientists to develop activities based on food and cooking (in fact molecular gastronomy knowledge) to raise public awareness of science. This project was named The Kitchen is a Laboratory (KiL) (Ciência Viva, n.d.-a; Mata et al., 2007) and involved scientists with different backgrounds. The diverse set of activities developed aimed to introduce, in a meaningful context to the audiences, principles of chemistry, physics, biology and microbiology, using them to explain common activities performed while preparing meals.

The interest of the public and school teachers was significant. Hand-outs prepared for the activities were an important factor to extend the scope and impact of the project. The feedback received demonstrated that some of the activities were frequently repeated in schools, integrated in school projects or even laboratory classes, and in science weeks.

Following the success of these activities, and in parallel with them, work was also conducted with professional chefs who wanted to enlarge their knowledge, and also benefit from scientific developments to improve traditional cooking techniques and introduce new ones. In this context, a collaborative project, C3 (Cozinha x Ciência x Colaboração - Cooking $\mathrm{x}$ Science $\mathrm{x}$ Collaboration), was launched $(\mathrm{C3}, 2008)$. Its aims were to deepen and strengthen the connections between scientists and cooking professionals in Portugal, in order to establish and explore forms of productive collaboration.

This work could reach a big audience as some elements of the KiL team, the author included, wrote for two years for a national newspaper (Diário de Notícias) on themes related to cooking and science (Diário de Notícias, 2004, 2006), as well as a monthly column in a magazine for professional chefs (InterMagazine) between 2005 and 2008. In addition, they participated in several TV programmes, particularly a series of 13 science dissemination TV shows, each of them including about 5 minutes of KiL activities. 
This project resulted also in a book A Cozinha é um Laboratório (Guerreiro \& Mata, 2010) composed of 37 short texts (about 3 pages each), profusely illustrated. The KiL project can also be considered the seed that led in 2010/2011 to the launch of an MSc degree programme in Gastronomical Sciences (FCT, 2012), a joint initiative of Faculdade de Ciências e Tecnologia - Universidade Nova de Lisboa and Instituto Superior de Agronomia - Universidade Técnica de Lisboa. The goal of this programme is to provide thorough scientific and technological training in food science, but integrating it into a comprehensive technical and cultural approach.

\section{From The Kitchen is a Laboratory to the Pollen Project}

\subsection{Using Molecular Gastronomy for Science Education}

Food and cooking are topics with great potential to be used in science education (Barham et al., 2010; Fooladi, 2010; J ones, 2011; Mata et al., 2007; Miles \& Backman, 2009; This, n.d.; van der Linden, McClements \& Ubbink, 2007). The experience with the KiL project in using food and cooking to discuss issues like the characteristics of science and scientists, or to introduce concepts and theories, enabled the identification of some strengths of this approach. These included namely its potential to reinforce the links between science and daily life; to contribute to the valuing of the empirical knowledge of amateur cooks (particularly family members); and to incentivise cross-generational communication. These were confirmed in the work developed for the Pollen project.

This approach, exploring a theme that is significant to everyone regardless of age, gender or cultural factors, and which is often invested with strong positive feelings, contributed to motivate teachers, children and families to get involved in the project and to work together to reach the goals. Food and cooking worked as a bridge to overcome the gap between the culture of the community involved in the project and the culture of science very far removed from its daily life. This approach also allowed the families to contribute actively with their specific knowledge. Their knowledge was used as the object of study for the children, and thus became more valued. This was a process that could create a stimulating learning environment for all, as all acted as both producers and recipients of knowledge.

The themes and activities proposed create teaching/learning contexts based around food which are fun and stimulate the senses. Therefore, in addition to promoting an IBSE, this approach helps to develop interest in an environment-friendly healthy diet as well as in the associated social and emotional values, including learning about other cultures and their food and cooking traditions; and sharing food, thus creating or strengthening emotional bonds.

In the application of such a methodology, it is however important to not let the "entertainment" component of the activities become too dominant or central. This 
happened in several situations, particularly when the teachers responsible were not very familiar with science concepts and culture. It is essential to make the teachers aware that the main purpose of the activities is science education. It is not enough just to do cooking activities or to see the spectacular results of science; the fundamental aspects are to observe and ask questions, plan and carry out valid experiments, record, analyze results and draw conclusions. Dialogue is a vital tool to allow for greater understanding of results and concepts, and more in-depth reflection on them and their relation with reality.

A fundamental part of the Pollen project was the teachers training component. This, as referred by Harlen (2004), is essential to overcome the difficulties mentioned above and to allow for more long-lasting project effects. Another aspect that received a great deal of attention was the exchange of experiences between teachers, which turned out to be a particularly enriching feature of the project. This training allowed the teachers to gain confidence in their ability to teach experimental science and technology, and to understand the role that they must play in this process.

Teachers comments about their experience in the Pollen project included:

“It wasn't easy for me to start doing experiments because I didn't feel comfortable with science and experimenting and I didn't have the necessary language to start doing the experiments. The students weren't exactly open to the idea of how to do an experiment, formulate hypotheses or interpret what they saw. Nevertheless, the experiments went well, their curiosity grew and soon everyone wanted to take part.

[...]

Learning through experience is something inherently personal which we don't forget because it makes sense to us. By doing the experiments, we have consolidated the information we worked on and the children are now able to apply it to different situations.

This project was the one which had the most influence on my teaching practice and the way I now think and act in the classroom."

"Participating in the Pollen project was a very enriching experience for me. I hope that this work has helped me instil a love of science in my pupils.

The children were always interested and willing to take part in the experimental activities and often repeated them at home with their families, thereby involving them in the project too. This meant the child was the channel through which science flowed into the family at home."

"The science concepts I acquired allowed me to look at daily life subjects in a different way. My initial apprehensions about inquiry-based science education were dispelled as I realised that experimental science activities are very motivating and excellent promoters of a crossdisciplinary approach, and also as my self-confidence grew. The learning units proposed were very closely related to kids' daily life and very easy to adapt to groups at different ages and stages of development. I think that with these activities my students could discover and understand a set of elements of daily life through their own actions. In fact, it wasn't only the kids but also their families, as they were always eager to transmit their achievements at home and repeat the activities with their families." 


\subsection{Food and Cooking - One topic, many activities}

Food and cooking topics can generate a wide range of science activities (Fooladi, 2010; Jones, 2011; Miles \& Backman, 2009; This, n.d)., which can be adapted to different age groups and objectives. They also allow for inter-disciplinary teaching in which food is used as the starting point for approaching other curriculum areas, such as environment studies, history, mathematics, arts, science and languages. The KiL and Pollen projects included several innovative methodologies and techniques for broaching food-related science issues. Children also had the opportunity to learn about available sources of information (books, internet, experts, study trips...) and, above all, learn to select relevant information. In this process, study trips and the assistance of those who are most familiar with the theme are particularly important, as they contribute to create ties with the community, bring the children into contact with different professions, and provide them with an understanding of the role played by these professionals.

Some of the types of activities explored in the KiL and Pollen projects are described below.

1 - The five senses and their role in food perception and enjoyment.

An awareness-raising and entertaining programme for learning about taste was developed which demonstrated the importance of each one of the senses in our overall perception of food and how they complement each other. The children used their five senses to examine some foods and classify them according to the characteristics they noted.

Starting with this activity, it was also possible to discuss with the children how a specific food may be pleasant for some and unpleasant for others, and examine how this related to personal and cultural characteristics and habits. As taste is personal but it can also be educated, it was considered important to make children think about food they like, try to understand why they like it and then guide them to discover new flavours. In this process, children were stimulated to make descriptions as accurate and expressive as possible.

2 - Exploration of the tasks involved in preparing a meal on the basis of crossdisciplinarity.

This can involve the choice of recipes - based on the availability of the ingredients (geographical and seasonal) and their nutritional characteristics - reading the recipes, compiling lists of ingredients, calculating the necessary amounts depending on the number of people eating, calculating the costs, acquiring the ingredients, explaining kitchen techniques and "tricks", and decorating the dishes and the tables... These activities have a great potential to use food and cooking not only for science education, but also to introduce aspects that touch on all the curriculum areas. 
3 - Experimental science education activities based on inquiry-based science learning in which the starting point is food and cooking processes.

Several learning units were developed, including:

Water in Food

Microbes - some are bad but others are very useful...

Vegetables - beautiful, colorful, and tasty...

So much to learn and enjoy!

Understanding baking
- Why do we cut chestnuts to cook them?

- Making popcorn - why does corn pop?

- Roasting potatoes in the microwave - why do we need to pierce their skin?

- Baking bread - what is the role of yeast?

- Makingjam - why does it keep for so long?

- How do they grow?

- Why do we water them?

- What vegetables do you eat? (Learning about vegetables from different places)

- Cooking soup - which parts of the plants do we eat?

- What is the role of baking powder?

4 - Activities like visiting farms and markets, or even creating school vegetable gardens as a way of learning about plants and animals, and of discovering a greater variety of food, introducing it to the children's diet and familiarising them with healthy nutritional products.

It is important that children get to learn more about food and that they discuss its characteristics and origins (animal, plant, food manufactured from animal or plant products...), the processes involved in its production and, where appropriate, when the food is in season, which means that it is tastier and more environmentally-sustainable.

5 - Respecting and valuing different ethnicities and cultures.

Cultural and ethnic diversity in schools is often quite large. Food is an excellent way to learn about other cultures and gain respect for differences. Activities which involve children and families from other cultures allowed students to get to know their traditional products and dishes. This can make a very positive contribution to integration. It was also a very effective way of involving the families in school activities and attaching importance to their cooperation. 


\subsection{Involving families in inquiry-based science education}

Analysis of the work done by the teachers in the KiL and Pollen projects led to the identification of some effective ways of involving families in IBSE:

1. Parents' meetings, as well as informal talks with families, can be used to inform them about IBSE projects and motivate them to collaborate.

2. Asking for families' feedback about the work done and the impact of the IBSE activities in the children.

3. Exhibitions of experiments, records and photos in common areas of the school.

4. Keeping a "Project corner" in the classroom.

5. Involving families in the activities by suggesting some experimental science activities as "homework" and asking for feedback.

6. Asking for families' collaboration for activities done at school. This can be done by asking for materials or even, and most interestingly, by sharing their knowledge and experience. For example some grandparents helped with the school vegetable garden; some parents working in bakeries helped in bread-baking activities.

7. Poster exhibitions in local shops or other community areas, and news in local council magazines. This makes kids and families proud of the work done, as it attracts interest from other people, values their achievements and motivates children to work better and families to collaborate.

8. Taking advantage of social celebrations (Mother's day, Father's Day, Easter, Christmas; School parties...).

9. Science Fairs at school or in other places (local council events, shopping centres...).

10. Producing and distributing documents explaining science issues related to daily life in a simple and attractive way (Ciência Viva, 2012) or even giving some guidance for experimental activities for the family to do together. An example of this is the booklet "The fun-flavoured way to learn science. Experiments for the family to do together" (Pollen Team - Portugal, 2009) developed under the Pollen project and available for download.

\section{Conclusions}

Food and cooking are topics with widespread appeal and the interest that these topics generate can make a positive contribution to a better understanding of the role of science and scientists in everyday life. The science dissemination project The Kitchen is a Laboratory was very well received by the general public and acquired unexpected proportions and developments that allowed reaching a much larger and diverse public than initially foreseen.

Food and cooking can also be used to create teacher/ learning environments particularly suited to motivate and engage teachers and students in science activities, including amongst those who are not very familiar with a science culture. The work carried under the 
auspices of the Pollen: Seed Cities for Science projects, and particularly the introduction of IBSE based on food and cooking, was warmly welcomed by the children and teachers involved. Considering the feedback and results, it can be concluded that this project contributed to raising teacher awareness and training them in science and technology experimental education. Many of the teachers grasped the ideas and methodologies that were at the heart of the project very effectively and gained confidence in their ability to deal with science and technology experimental education. Some of them have already begun to deal with other themes using the same methodology or are even studying other aspects of the themes covered in the project.

However, there is still a long way to go to achieve a general and effective integration of science experimental education, and particularly of IBSE, in pre-school and junior schools. This can only become a reality through an extensive in-depth teacher training process. The approach described can contribute to this goal and to raise the appeal of science and change the ways in which people see scientific knowledge and relate to it.

The use of molecular gastronomy for science dissemination activities and science education is still very limited. The work conducted as part of these projects constitutes only a scratching of the surface, and there remain many large and interesting challenges to explore.

\section{References}

Aikenhead, G. S., \&J egede, O. J . (1999). Cross-Cultural Science Education: A Cognitive Explanation of a Cultural Phenomenon. J ournal of Research in Science Teaching, 36(3), 269- 287.

Barham, P., Skibsted, L. H., Bredie, W. L. P., Frøst, M. B., Møller, P., Risbo, J., ... Mortensen, L. M. (2010). Molecular Gastronomy: A New Emerging Scientific Discipline. Chemical Reviews, 110, 2313- 2365.

C3 (2008). C3 - Cozinha x Ciência x Colaboração. Retrieved 29th Nov 2012 from http:/ / c-aocubo.blogspot.pt/2008/09/c-ao-cubo.html

Ciência Viva (n.d.-a). A Cozinha é um Laboratório. Retrieved 29th Nov 2012 from http:// www.cienciaviva.pt/ divulgacao/ cozinha/

Ciência Viva (n.d.-b). Ciência Viva - The Programme. Retrieved 29th Nov 2012 from http:// www.cienciaviva.pt/ cienciaviva/ programa/

Ciência Viva (2012). Guide 4 - In Lisbon, Discovering Science and Technology - Tastes of the City. Retrieved 29th Nov 2012 from http:// www.pavconhecimento.pt/roteiro4_sabores_cidade/ en/home.html

Diário de Notícias (2004). A cebola que nos faz chorar. Retrieved 29 $9^{\text {th }}$ Nov 2012 from http:// www.dn.pt/Inicio/interior.aspx?content_id $=590261$

Diário de Notícias (2006). A ciência de fazer bolos. Retrieved 29th Nov 2012 from http:/ / www.dn.pt/Inicio/interior.aspx?content_id=644135

FCT (2012). Mestrado em Ciências Gastronómicas. Retrieved 29th Nov 2012 from http:// www.fct.unl.pt/ candidato/ mestrados/ mestrado-em-ciencias-gastronomicas

Fooladi, E. (2010). "Kitchen Stories" - Assertions about Food and Cooking as a Framework for Teaching Argumentation. Retrieved 29 $9^{\text {th }}$ Nov 2012 from http:/ / files.ecetera.si/ IOSTE/ 505.pdf

Guerreiro, M., \& Mata, P. (2010). A Cozinha é um Laboratório (3rd ed.). Lisboa: Fonte da Palavra. 
Harlen, W. (2004). Evaluating Inquiry-Based Science Developments. Retrieved $29^{\text {th }}$ Nov 2012 from http:// www.nsrconline.org/pdf/NAS_paper_eval_inquiry_science.pdf

J ones, C. D. (2011). The Kitchen is Your Laboratory: A Research-Based Term-Paper Assignement in a Science Writing Course. J ournal of Chemical Education, 88(8), 1062- 1068.

Mata, P., Bettencourt, C., Lino, M. J ., \& Sousa-Paiva, M. (2004). Cientistas de Palmo e Meio - Uma Brincadeira Muito Séria. Análise Psicológica, XXII(1), 169-174. English version retrieved $28^{\text {th }}$ Nov 2012 from http:// www.cienciaviva.pt/ projectos/ scienceduc/ youngscientists.pdf

Mata, P., Noronha, A., Gomes da Costa, A., Guerreiro, M., \&Loureiro-Dias, M. C. (2007). Science Can Be Tasty. In H. This \&T. Eklund (Eds.), Proceedings of the EURO FOOD CHEM XIV (vol. 1, pp. 65 - 67). Paris: Société Française de Chimie.

Miles, D. T., \& Backman, J. K. (2009). Science of Food and Cooking: A Non-Science Majors Course. J ournal of Chemical Education, 86(3), 311- 315.

Pollen (n.d.). Pollen: Seed Cities for Science. Retrieved 29th Nov 2012 from http:/ / www.polleneuropa.net

Pollen Team - Portugal (2009).The Fun-Flavoured Way to Learn Science. Retrieved $29^{\text {th }}$ Nov 2012 from http:// www.cienciaviva.pt/projectos/pollen/livroEN_pollen.pdf

This, H. (n.d.). Les Initiatives de Diffusion des Connaissances. Retrieved 29th Nov 2012 from https:// sites.google.com/ site/ travauxdehervethis/Home/ applications-pedagogiques

van der Linden, E., McClements, D. J ., \& Ubbink, J . (2007). Molecular Gastronomy: A Food Fad or an Interface for Science-Based Cooking? Food Biophysics, 3(2), 246- 254.

\section{Acknowledgements}

The author thanks Margarida Guerreiro for more than 10 years of lively discussions and an extensive and productive collaboration. The author also wants to gratefully acknowledge the support of Rosário Oliveira, coordinator of the Portuguese team on the Pollen project. 
MATA 